\title{
News Shocks and the Term Structure of Interest Rates: Reply \\ Online Appendix
}

\author{
André Kurmann \\ Drexel University
}

\author{
Christopher Otrok \\ University of Missouri \\ Federal Reserve Bank of St. Louis
}

\section{March 14, 2017}

This appendix provides further evidence about the relation between slope shocks and news shocks as discussed in our reply to the comment by Cascaldi-Garcia (2017) on our original paper (Kurmann, A. and C. M. Otrok. 2013. "News Shocks and the Term Structure of Interest Rates." American Economic Review, 103(6): 2612-32). In particular, this appendix shows that the impulse responses to a news shock become more robust to the use of revised vintages of adjusted TFP when (i) the news shock is identified as in Kurmann and Sims (2017); or (ii) when a larger VAR is used. In this latter case, the results are not affected by whether real aggregates are population-adjusted or not

The variables used in the different VARs below are:

- Fernald's utilization-corrected measure of TFP (either December 2007 or March 2016 vintage)

- Real personal consumption expenditures

- Real gross private domestic investment

- Real GDP

- Inflation measured by the growth rate in the GDP deflator

- Federal Funds rate

- Spread between 5-year zero coupon yield and Federal Funds rate

- Shiller's S\&P500 composite index, deflated by CPI index.

In keeping with the original paper, all the VARs are VARs are estimated with 4 lags subject to a Minnesota prior for the sample period 1959:2-2005:2. 


\section{Additional results for the baseline VAR}

We start with reporting additional results for the baseline VAR used in the paper that contains the slope, adjusted TFP, consumption, inflation, and the Fed funds rate. As in main text, consumption is population adjusted.

Figure A1 reports the impulse responses to a slope shock. Here and below, black solid lines refer to median responses and grey bands to corresponding 16 to 84 percent coverage intervals for the VAR estimated with the 2016 vintage of adjusted TFP while red dash-dotted lines refer to median responses and red dashed lines to corresponding 16 to 84 percent coverage intervals for the VAR estimated with the 2007 vintage.

Figure A1. Impulse responses to a slope shock for the baseline VAR
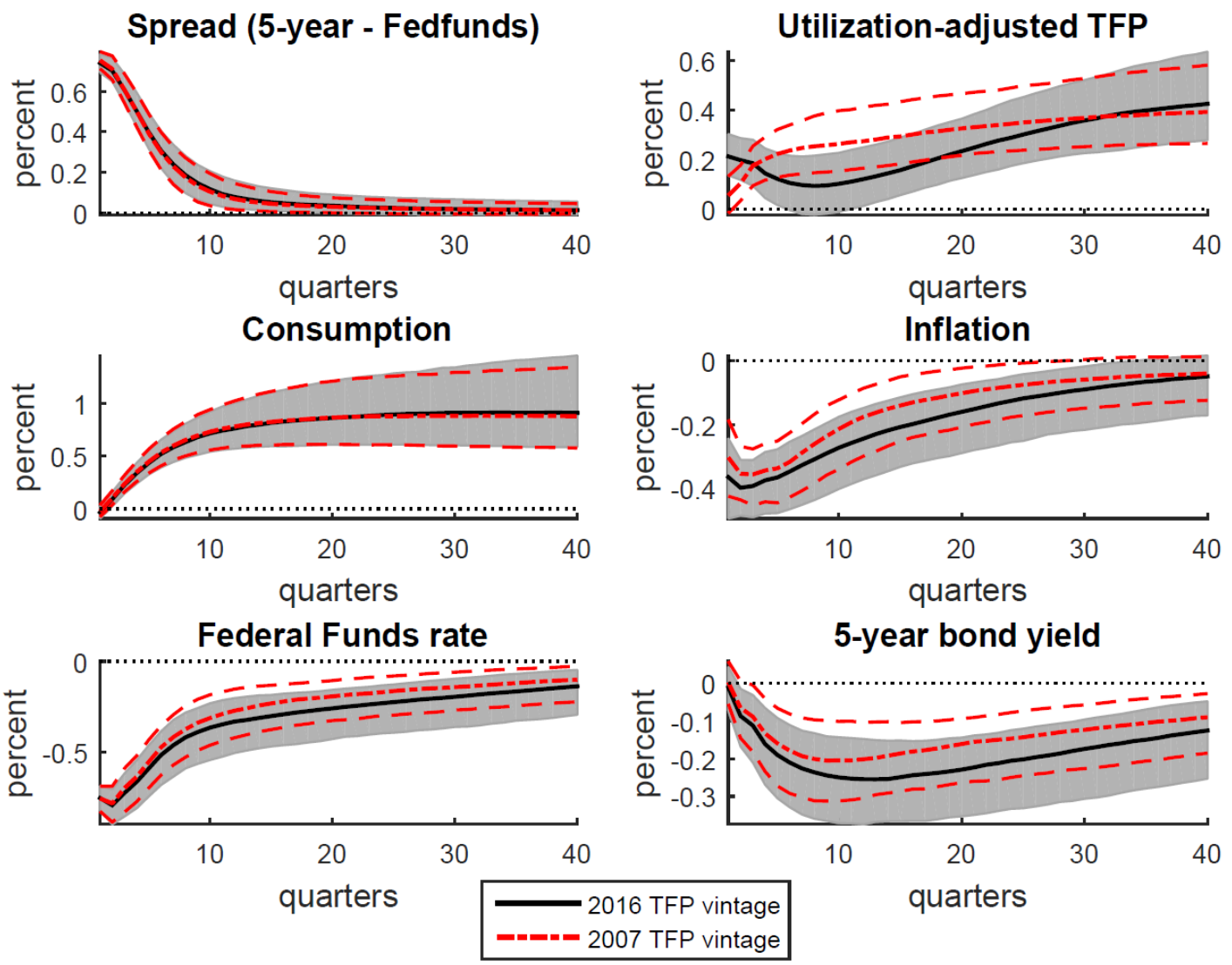

The impulse responses are almost identical to ones reported in Figure 2 of Cascaldi-Garcia (2016). Adjusting consumption for population does not change the results for the slope shock. 
Figure A2 reports the impulse responses to a news shock identified as in Kurmann and Sims (2017); i.e. without imposing orthogonality to current productivity and maximizing the MFEV objective at the 80 quarter horizon only.

\section{Figure A2. Impulse responses to news shock identified as in Kurmann and Sims (2017) for the baseline VAR}
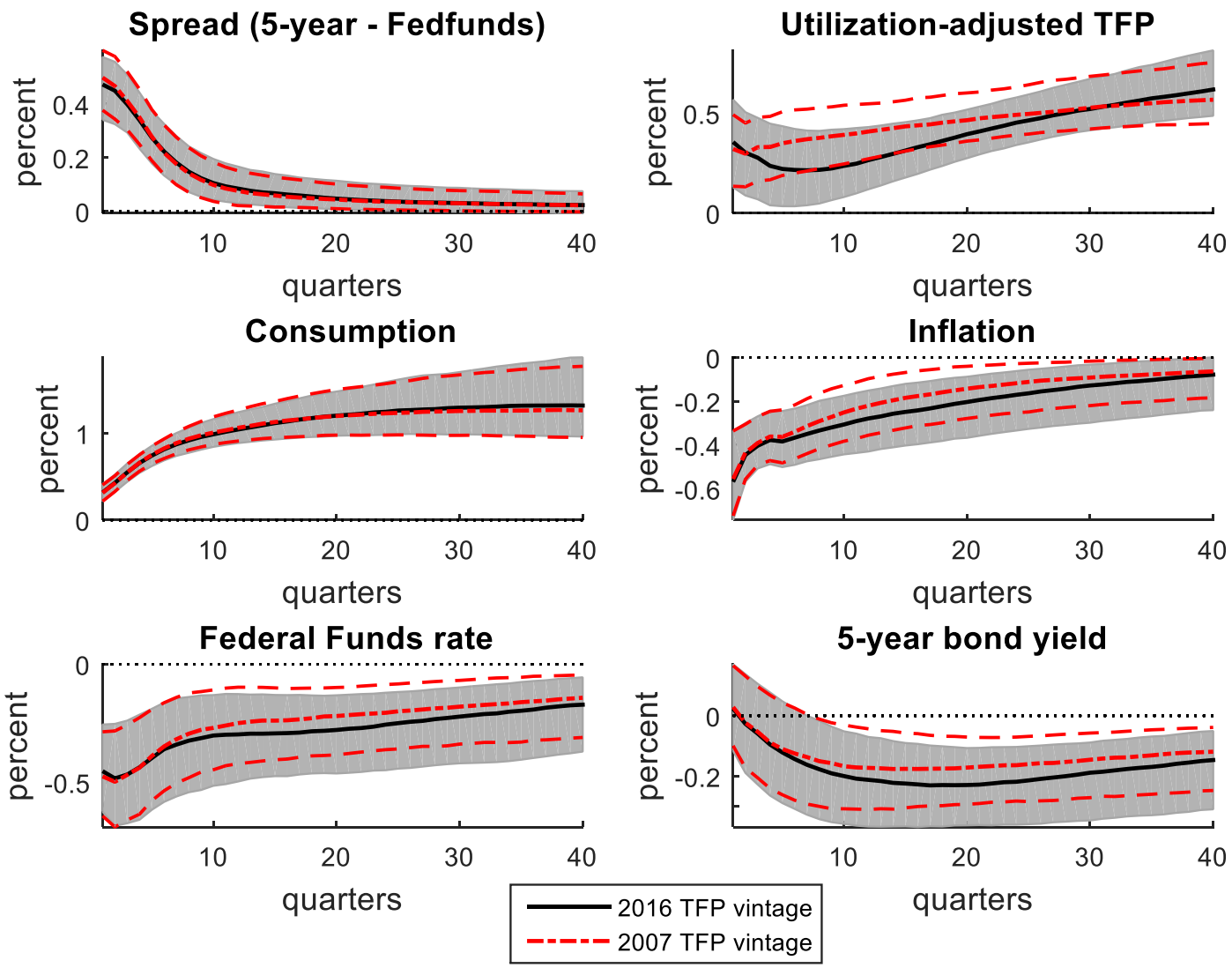

The impulse responses estimated based on the two vintages lie essentially on top of each other, except for the impulse response of adjusted TFP. Notice that these impulse responses of adjusted TFP are close to the ones reported in response to the slope shock reported in Figure A1.

The correlation of this news shock with the slope shock is 0.73 for both the 2007 vintage and the 2016 vintage of adjusted TFP.

In sum, Kurmann and Sims' (2017) identification of news shock is robust to the vintage of adjusted TFP used and provides a substantially closer fit with the slope shock. 


\section{Results for larger VAR}

Next, we report results for the larger VAR specifications in Kurmann and Otrok (2013) that adds gross domestic product, investment, and the real stock price to the variables of the baseline specification. From hereon, none of the real aggregates is population-adjusted to show that for this larger VAR, population adjustment is not necessary to recover the relationship between the slope shock and the news shock (none of the results would change if instead, real aggregates were population-adjusted - in fact, the fit between the slope shock and the news shock would be slighly better).

Figure A3 reports the impulse responses to the slope shock for this larger VAR (to save on space, we do not report the impulse response of the long rate which is constructed as the sum of the spread and the Federal Funds rate).

Figure A3. Impulse responses to a slope shock for the larger VAR
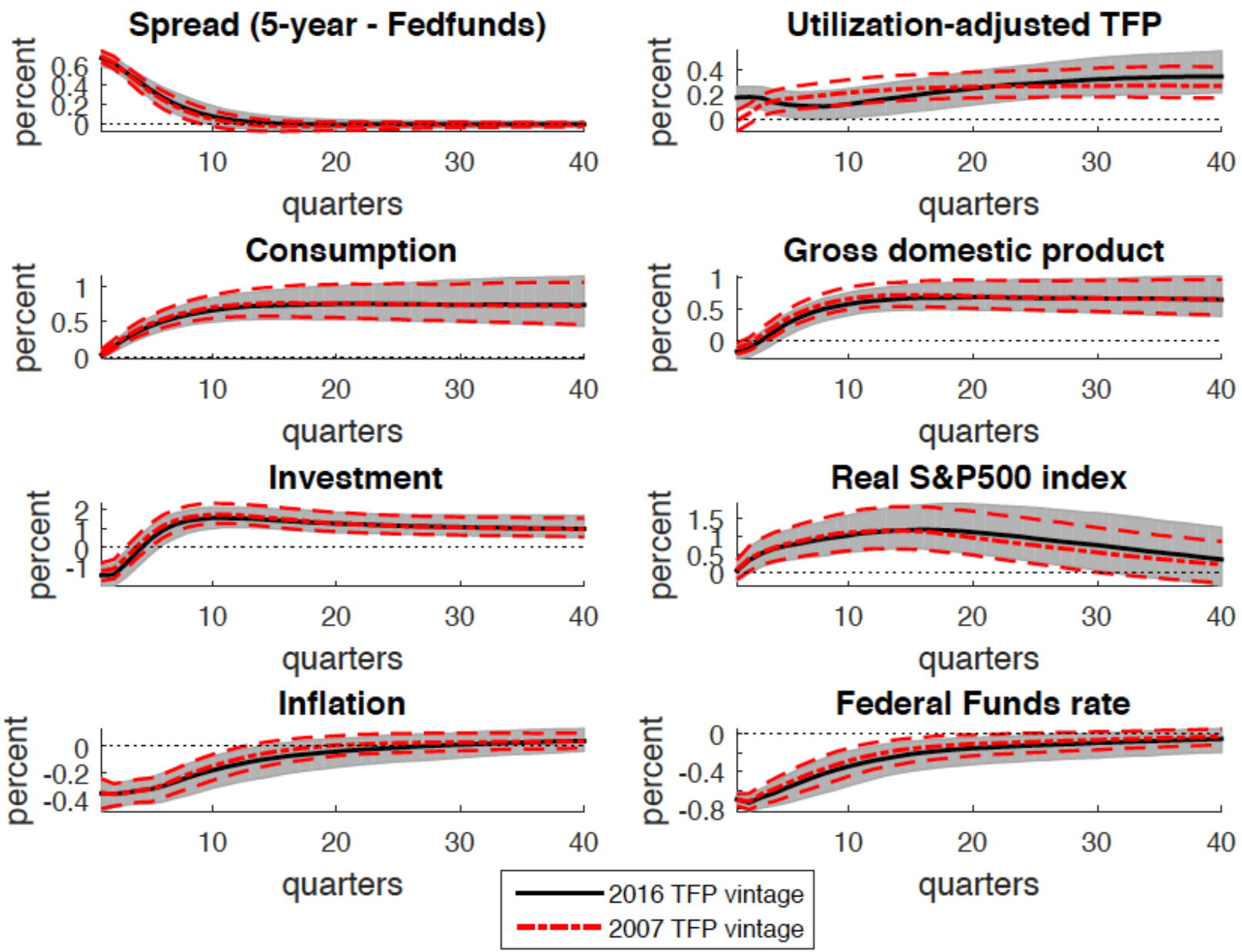

For the variables included in the baseline VAR, the results are very similar to ones reported in Figure A1. Both GDP and investment respond similarly to consumption with a gradual increase 
to a new permanent level. Investment drops significantly on impact. The real stock price reacts in a hump-shaped pattern.

Figure A4 reports the impulse responses of the same larger VAR to the news shock identified over the 0-40 quarter horizon as in Barsky and Sims (2010) and Kurmann and Otrok (2013).

Figure A4. Impulse responses to a 0-40 news shock for the larger VAR
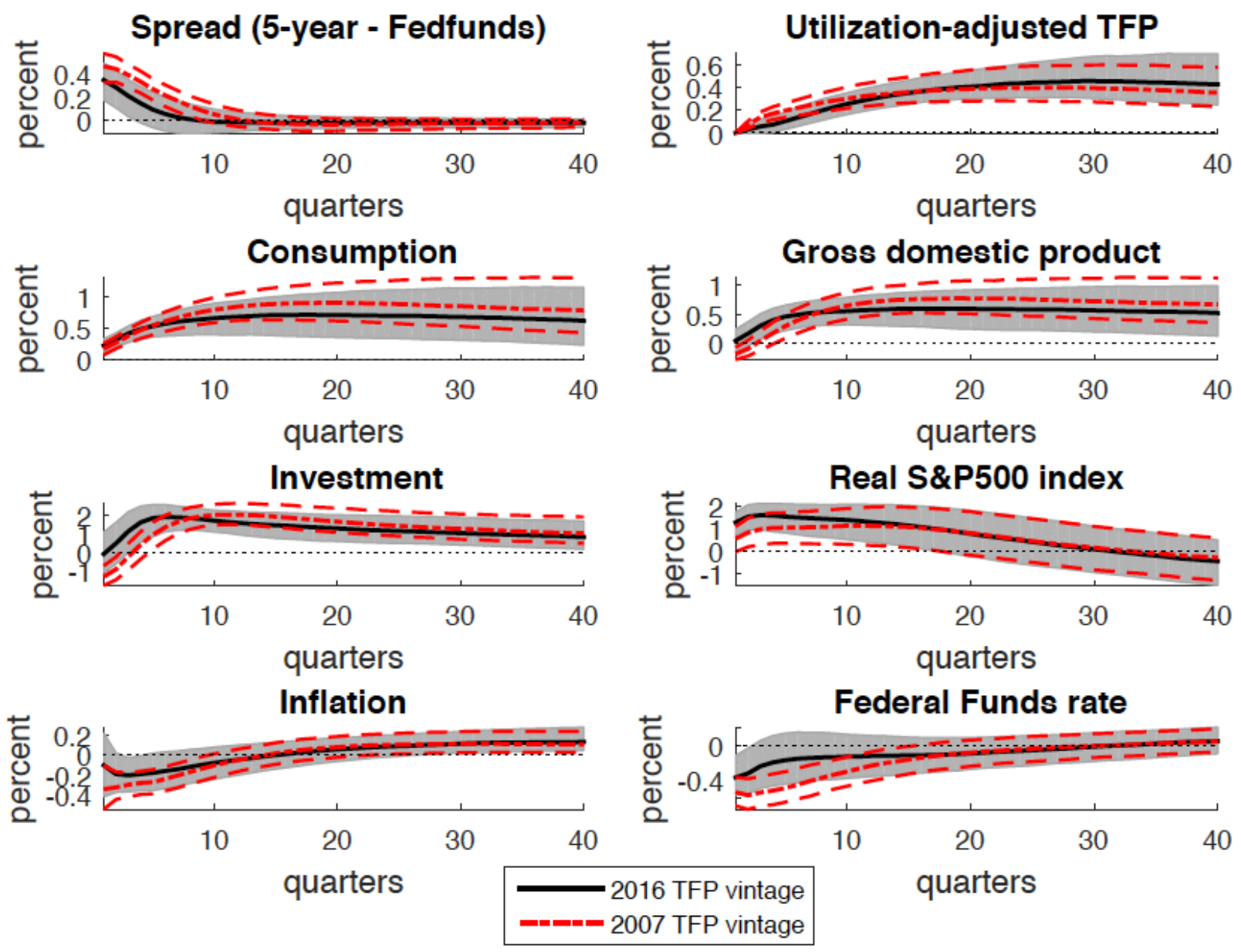

There are some differences in impulse responses across the two vintages, but what is noticeable is the similarity in response of adjusted TFP in this larger system. For both vintages, adjusted TFP starts increasing one period after the news shock. Indeed, these responses are identical to whether the rotation condition discussed in the main text is imposed at the 5 quarter horizon or the 40 quarter horizon. The resulting shocks are essentially the same.

The correlation of this news shock with the slope shock is 0.85 for the 2007 vintage and 0.48 for the 2016 vintage of adjusted TFP. 
Figure A5 reports the impulse responses to a news shock as identified by Kurmann and Sims (2017).

\section{Figure A5. Impulse responses to a news shock identified as in Kurmann and Sims (2017) for the larger VAR}
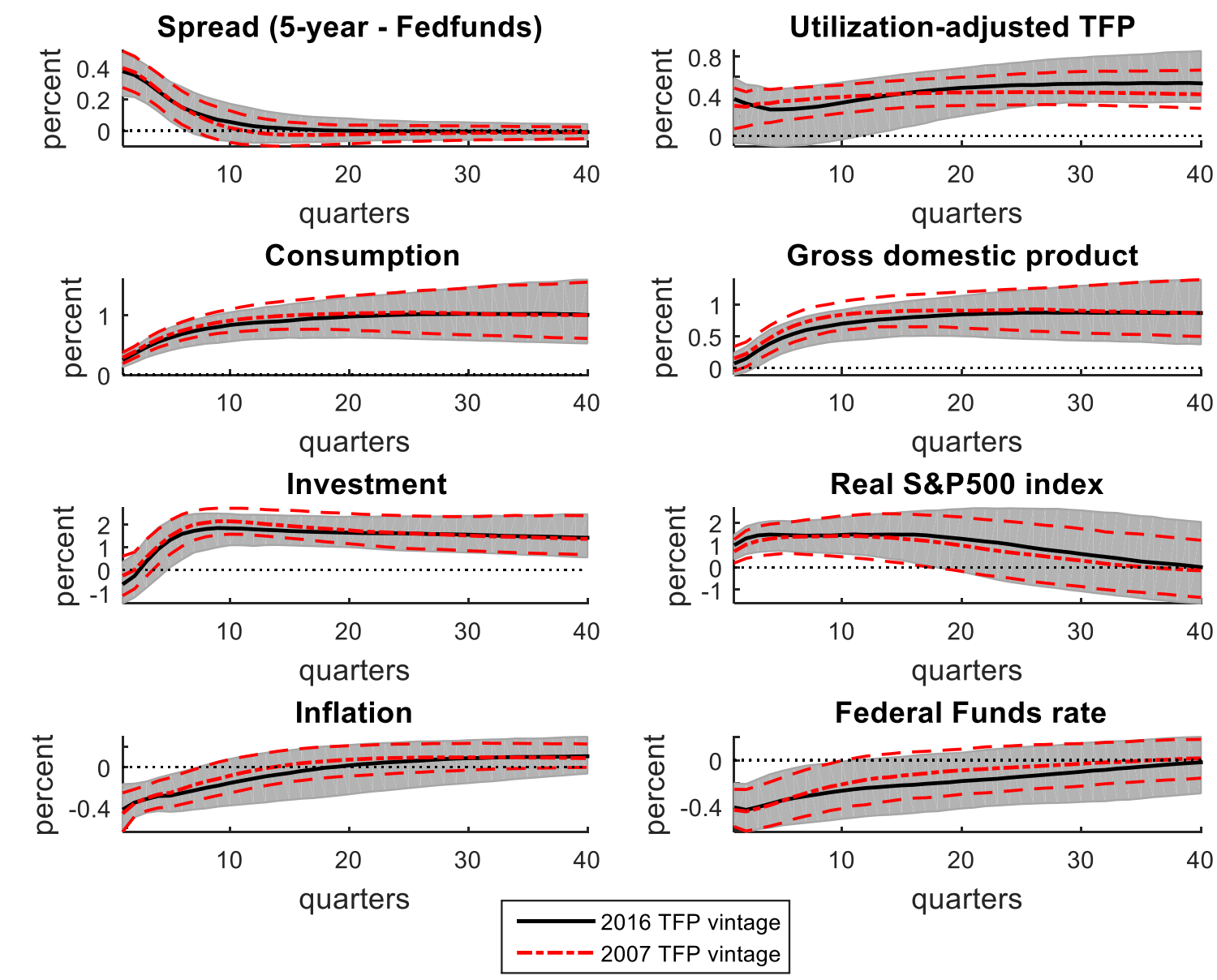

Federal Funds rate

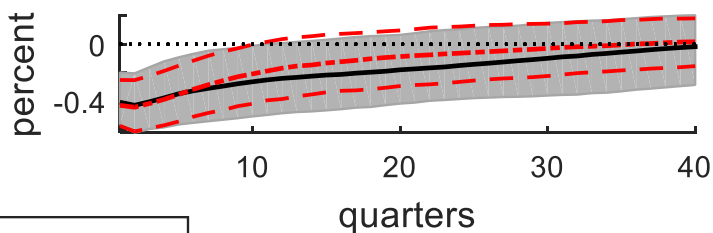

As for the baseline VAR, the impulse responses are very much robust to the choice of vintage of adjusted TFP. Adjusted TFP now reacts similarly for both vintages and the response on impact is not significantly different from zero.

The correlation of this news shock with the slope shock is 0.69 for both the 2007 vintage and the 2016 vintage of adjusted TFP. 